https://doi.org/10.36105/iut.2019n29.05

\title{
DE LOS EFECTOS DEL ACUERDO ARBITRAL TRAS LA EXTINCIÓN POR NOVACIÓN DE LA OBLIGACIÓN QUE LO CONTIENE
}

\author{
THE EFFECTS OF THE ARBITRAL AGREEMENT \\ AFTERTHE EXTINCTION BY NOVATION OF THE \\ OBLIGATION CONTAINING IT
}

\author{
Paul G. Renaud Courtney* \\ Universidad Anáhuac México, México \\ paul.renaud@anahuac.mx
}

\section{RESUMEN:}

El principio de autonomía o separabilidad del acuerdo arbitral impide que éste se destruya cuando la obligación que lo contiene se extingue por novación. La cuestión es dilucidar si ese pacto de arbitraje que sobrevive a la novación se transfiere a la nueva relación jurídica o no, y, en todo caso, determinar cuál será su utilidad y cuales sus efectos una vez desaparecida la obligación específica para la cual fue establecido por las partes.

\section{Palabras clave:}

Novación, arbitraje, acuerdo arbitral, separabilidad del acuerdo arbitral, autonomía del acuerdo arbitral, relación jurídica.

\section{ABSTRACT}

The principle of autonomy or separability of the arbitration agreement prevents it from being destroyed when the obligation that contains it is extinguished by novation. The question is to determine if this arbitration agreement that survives the novation is transferred to the new legal relationship or not, and, in any case, determine what will be its usefulness and what its effects will be once the specific obligation for which it was established by the parties has disappeared.

\footnotetext{
Abogado por la Escuela Libre de Derecho, Candidato a Doctor en Derecho de la Empresa por la Universidad Anáhuac México en convenio con la Universidad Complutense de Madrid, profesor de Obligaciones y Contratos civiles en la Facultad de Derecho de la Universidad Anáhuac México, Coordinador Académico de Derecho Privado y Mediación en la misma institución.
} 


\section{Keywords:}

Novation, arbitration, arbitration agreement, autonomy of the arbitration agreement, separability of the arbitration agreement, legal relationship.

\section{NOTA PRELIMINAR}

La eficacia extintiva de la novación es incuestionable. Llevada a cabo conforme a los lineamientos que para su procedencia son previstos por la ley, surte el doble efecto de extinguir por un lado una obligación previamente existente $y$, por el otro, el de dar nacimiento a una nueva obligación que vincula a las mismas partes y que sustituye a la anterior.

En estas condiciones, se plantea en primer término la necesidad de precisar si la fuerza extintiva de la novación se extiende o no al convenio arbitral que suscribieron las partes para definir el mecanismo de solución de las controversias que hubieran podido surgir con motivo de la relación jurídica que se extingue, tomando especialmente en consideración el principio de autonomía —o separabilidad- del acuerdo arbitral.

Prima facie, la respuesta a dicho planteamiento se presenta evidente: toda vez que por autonomía o separabilidad del acuerdo arbitral se entiende que este pacto no es propiamente accesorio sino independiente en su totalidad del contrato en el cual se encuentra incorporado y que en realidad estamos en presencia de dos relaciones jurídicas distintas, es de concluirse que la novación que produce la extinción de la obligación respecto de la cual se estableció por las partes el sometimiento al arbitraje para resolver en su caso las disputas que de ella derivasen, no tiene el alcance de extinguir per se este acuerdo arbitral, sino que sobrevive a la supresión de tal obligación.

Por supuesto, el asunto que nos ocupa no concluye — ni podría concluir - en este punto. Más allá de la meridiana explicación en el sentido de que si la intención de las partes al acordar la novación incluye la eliminación del convenio arbitral, debe hacerse constar dicha voluntad expresamente, manifestarla en específico para tal efecto y de manera adicional a la de novar la obligación a la cual se encuentra vinculado, las cuestiones que no han quedado puntualmente esclarecidas son las referentes a que si bien es innegable que la novación de una obligación no extingue por sí sola el acuerdo arbitral que le corresponde sino que subsiste con vida propia con posterioridad a la novación, ¿para qué subsiste?, ¿sus efectos trascienden a la nueva obligación?, ¿es jurídicamente relevante que ese acuerdo arbitral siga teniendo existencia y eficacia después de la extinción de la relación jurídica concreta para la cual fue establecido convencionalmente por la partes?

Abordar el análisis de estos planteamientos y presentar nuestros personales argumentos conclusivos en torno a los mismos es el objetivo de este trabajo.

\section{DINÁMICA DE LA NOVACIÓN}

El panorama evolutivo de esta particular forma de extinción de las obligaciones nos presenta de ella distintas modalidades. En primer término, la novación objetiva, que se da cuando en la sustitución de la antigua obligación por la nueva 
encontramos una diferencia sustancial en algún elemento que afecta la esencia de la relación jurídica, como puede ser el objeto, la causa o la condición. En segundo lugar, existe la novación subjetiva, que se caracteriza por el cambio de alguno de los sujetos de la relación, de manera que la nueva obligación cuenta con un acreedor o un deudor diferente respecto de la primitiva. En nuestro país, esta última forma de novación quedó suprimida en la legislación civil de $1928,{ }^{1}$ la que introdujo la figura de la cesión de deudas dentro de los medios de trasmisión de las obligaciones, al lado de la cesión de derechos y la subrogación; esto implica que, a partir de la entrada en vigor de dicha legislación, el cambio de sujetos en una determinada relación jurídica obligacional no la extingue, sino que se mantiene la misma con diverso acreedor o deudor, según sea el caso.

En estas condiciones, haremos referencia específica a los elementos principales de la novación objetiva, a fin de estar en posibilidad de evidenciar sus alcances sobre el acuerdo arbitral.

En México, tanto el Código Civil Federal como el Código Civil para el Distrito Federal establecen en su respectivo artículo 2213: "Hay novación de contrato cuando las partes en él interesadas lo alteran substancialmente substituyendo una obligación nueva a la antigua", y precisa el artículo 2215 de ambos ordenamientos: "La novación nunca se presume, debe constar expresamente".

De manera general, la eficacia extintiva y creadora de la novación requiere del acuerdo de voluntades de las partes involucradas ${ }^{2} \mathrm{y}$, además, en todas las legislaciones que la regulan, tal eficacia está sujeta a la actualización de importantes condiciones:

a) La existencia de una obligación previa cuya extinción se pretende.

b) La creación de una nueva obligación que sustituye a la primera.

c) Una diferencia sustancial entre la obligación primitiva y la nueva.

d) El animus novandi de las partes, es decir, su intención de novar.

Se subraya la relevancia del nexo causal existente entre los dos primeros requisitos que hemos mencionado, pues resulta que de no extinguirse la obligación primitiva no podría crearse la nueva, y a la inversa, si esta última no naciera, la relación jurídica original no se extinguiría. Francisco de A. Sancho Rebullida, ${ }^{3}$ citando a Cossío, se expresa en el mismo sentido, indicando que "la extinción de la obligación primitiva no es solo el efecto, sino, además, la causa de la nueva, llamada a sustituirla, hasta el punto de que nacimiento y extinción se condicionan recíprocamente y la obligación nueva no se produce si la anterior era nula o inexistente y viceversa".

\footnotetext{
1 Nos referimos concretamente al entonces Código Civil para el Distrito y Territorios Federales en materia común y para toda la República en materia federal, promulgado en 1928 y con entrada en vigor el $1^{\circ}$ de octubre de 1932. El código civil de 1884 contemplaba la novación subjetiva en los siguientes términos: "Art. 1607. Hay también novación cuando un nuevo deudor es substituido al antiguo, que queda exonerado; o cuando el antiguo acreedor es substituido por otro, con quien queda obligado el deudor primitivo."

2 Al efecto, el artículo 2214 de los códigos civiles Federal y para el Distrito Federal dispone en ambos casos que la novación es un contrato, y como tal, está sujeto a las disposiciones respectivas, salvo las modificaciones que en dichos ordenamientos se previenen.

3 SANCHO, Francisco de A., La novación de las obligaciones, Barcelona, Nauta, S.A., 1964, p. 327.
} 
También es fundamental el requisito de que en la nueva obligación que nace como consecuencia de la novación se incluya un elemento nuevo - aliquid novique denote una diferencia sustancial respecto de la relación jurídica anterior, toda vez que, si no hay diferencia, o se trata de una diferencia no esencial o substancial, no tendrá lugar la novación. En su Tratado elemental de derecho civil, Planiol y Ripert, ${ }^{4}$ al explicar que la novación produce la extinción de una obligación por la creación de otra nueva, destinada a sustituirla, destacan la importancia de la diferencia sustancial que debe existir entre la obligación que se extingue y la que la reemplaza:

La segunda obligación debe diferir de la primera por un elemento nuevo, suficiente para que se distinga una de la otra: "Novatio enim a novo nomen accepit". Si faltase esta diferencia, la antigua obligación continuaría existiendo sin cambiar, y la pretendida novación no sería sino su reconocimiento o confirmación.

Este aspecto de la novación tiene especial trascendencia en la perspectiva del análisis que venimos realizando, pues debe dejarse en claro que la divergencia en lo esencial de ambas obligaciones implica por supuesto que se trata de dos relaciones jurídicas diferentes, una extinta y otra naciente, y que, salvo convenio expreso, lo que afectaba a la primera no puede seguir afectando a la segunda. Sobre este rasgo de la novación explican Fausto Rico, Patricio Garza y Mischel Cohen, ${ }^{5}$ que no cualquier variación en el objeto produce la extinción del vínculo obligatorio sino solamente la que sea sustancial, conforme a lo establecido por el artículo 2213 del código civil. "La modificación sustancial — continúan - es la que impide que algo siga siendo lo que es. Se contrapone a la accidental, que sólo afecta a las circunstancias del ser" (énfasis añadido).

Atendiendo a la naturaleza contractual de la novación, el animus novandi, es decir, la intención de novar, es otro elemento indispensable. En nuestro sistema jurídico se impone este requisito en el texto del artículo 2215 de nuestros códigos civiles Federal y para el Distrito Federal: "La novación nunca se presume, debe constar expresamente". La Suprema Corte de Justicia de la Nación también se ha pronunciado en diversas tesis por la indefectibilidad de esta precisión en el acto novatorio:

Novación. Requisitos PARA SU eXISTENCIA. La novación del contrato nunca se presume; está sujeta a las condiciones de todos los contratos y a las disposiciones expresas de la ley, sólo existe, cuando de manera clara aparece la intención de cambiar por otra, la obligación primitiva. ${ }^{6}$

NOVACIÓN. No EXISTE SI NO HAY VINCULACIÓN ENTRE LOS CONTRATOS CELEBRAdos. De conformidad con el artículo 2213 del Código Civil para el Distrito Federal, existe novación de un contrato cuando las partes en él interesadas lo alteran sustancialmente, sustituyendo una obligación nueva a la antigua; de manera que para

4 PLANIOL, Marcel y RIPERT, Georges, Tratado elemental de derecho civil, t. IV: Las obligaciones, 2a. ed., trad. de Jorge M. Cajica Jr., México, Cárdenas Editor y Distribuidor, 1991, p. 343.

5

6 Semanario Judicial de la Federación, Octava Época, Tomo V, Segunda Parte-1, enero-junio de 1990, tesis s/n, p. 308. 
que tenga lugar tal figura jurídica es indispensable que se reúnan los requisitos de existencia de una obligación anterior, la creación de otra obligación que la sustituya, la existencia de un elemento de esencia diferencial entre la primera y la nueva obligación y la exteriorización solemne de la voluntad o animus novandi; por tanto, si las partes no manifiestan su voluntad para sustituir la obligación anterior por una nueva, no existe novación. ${ }^{7}$

En estas condiciones, para que la novación surta sus efectos extintivo-creadores, es necesario que la voluntad de las partes en aras de que tales resultados se produzcan conste de manera indubitable, pues podría darse el caso de que un acuerdo no preciso en ese sentido tenga por consecuencia, no la novación, sino la renovación de la relación primigenia, o bien solamente la generación de una nueva obligación que en lo sucesivo coexistirá con la anterior. Planiol y Ripert ${ }^{8}$ destacan la importancia de la intención de novar "porque en todo caso puede crearse una nueva deuda al lado de la ya existente. Si el acreedor no consiente en perder su primera acción, subsistirán las dos obligaciones, una al lado de la otra, pero sin la extinción correlativa de la primera".

Naturalmente, el efecto extintivo de la novación alcanza tanto a la obligación principal original como a las obligaciones que le sean accesorias, sin embargo, puede el acreedor "por una reserva expresa, impedir la extinción de las obligaciones accesorias, que entonces pasan a la nueva". ${ }^{9}$ Esta posible reserva del acreedor respecto de las obligaciones accesorias no puede dar lugar a la subsistencia de garantías constituidas por terceros si no es que éstos, en sus respectivos casos, hubieran manifestado su conformidad para tal fin. ${ }^{10}$

Podemos observar que estas disposiciones legales hacen referencia a las obligaciones accesorias en general, de manera que no se trata de una alusión exclusiva a las garantías sino que también "comprende los intereses y otras deudas anexas". ${ }^{11}$

En este orden de ideas, si entendiéramos — como lo hacen algunos- que la cláusula arbitral contenida en un contrato determinado tiene carácter accesorio, tendríamos que concluir necesariamente que al extinguirse por novación la relación jurídica principal derivada de dicho contrato, el acuerdo de sujeción al arbitraje quedaría automáticamente extinguido, y habría que definir en estas circunstancias la curiosa posibilidad de que el acreedor "por una reserva expresa" pudiera impedir su extinción y entonces lograr que "pase" a la nueva obligación.

Por supuesto, esta consideración es inaceptable a la luz del principio de separabilidad del convenio arbitral, cuyos efectos y particularidades se tratan a continuación.

Semanario Judicial de la Federación, Séptima Época, Volumen 145-150, Cuarta Parte, tesis s/n, p. 387.

8 PLANIOL, Marcel y RIPERT, Georges, op. cit., pp. 349 y 350.

9 Artículo 2220 tanto del Código Civil Federal como del Código Civil para el Distrito Federal.

10 Artículo 2221 de los referidos códigos civiles: "El acreedor no puede reservarse el derecho de prenda o hipoteca de la obligación extinguida, si los bienes hipotecados o empeñados pertenecieren a terceros que no hubieren tenido parte en la novación. Tampoco puede reservarse la fianza sin consentimiento del fiador."

11 RICO, Fausto, et al., op. cit., p. 1139. 


\section{EL PRINCIPIO DE SEPARABILIDAD O AUTONOMÍA DEL ACUERDO ARBITRAL. ${ }^{12}$}

Uno de los principios de mayor relevancia y trascendencia en el ámbito del arbitraje comercial es sin duda alguna el de la autonomía o separabilidad del acuerdo arbitral. Este principio se traduce, grosso modo, en que el pacto de sujeción al arbitraje constante en la cláusula arbitral de un contrato determinado, constituye un acuerdo claramente independiente de éste, con "vida propia", y en consecuencia es inmune por regla general a las vicisitudes que puedan afectar la eficacia o validez del contrato que lo contiene, incluido el supuesto de su posible inexistencia.

Significa que la cláusula compromisoria se considera independiente del contrato principal del cual forma parte $y$, por ende, permanece vigente con posterioridad a su extinción. De hecho, sería totalmente contraproducente que el incumplimiento del contrato o la petición de su nulidad bastaran para poner fin también a la vigencia de la cláusula compromisoria, ya que es una de las situaciones en las que más se precisa dicha cláusula. ${ }^{13}$

El principio de separabilidad del acuerdo arbitral tiene amplísimo reconocimiento y enorme aceptación a nivel internacional. Particularmente se aprecia su recepción por una gran cantidad de países que han adoptado en su legislación interna los lineamientos de la Ley Modelo de la CNUDMI ${ }^{14}$ sobre Arbitraje Comercial Internacional, la que lo consigna expresamente en el párrafo 1) de su artículo 16:

1) El tribunal arbitral estará facultado para decidir acerca de su propia competencia, incluso sobre las excepciones relativas a la existencia o a la validez del acuerdo de arbitraje. A ese efecto, una cláusula compromisoria que forme parte de un contrato se considerará como un acuerdo independiente de las demás estipulaciones del contrato. La decisión del tribunal arbitral de que el contrato es nulo no entrañará ipso jure la nulidad de la cláusula compromisoria. ${ }^{15}$ (Énfasis añadido)

México adopta la Ley Modelo en 1993 y a partir de entonces quedó contemplado el principio de separabilidad del convenio arbitral en el texto del artículo 1432 del código de comercio, en los mismos términos. ${ }^{16}$

12 Conocido también como principio de independencia o de "vida propia" del acuerdo arbitral.

13 REDFERN, Alan y HUNTER, Martin et al., Teoría y práctica del arbitraje comercial internacional, 4a. ed. en español revisada y adaptada por Noiana Marigo y Felipe Ossa, Editorial Aranzadi, Navarra, 2007, p. 257.

14 Comisión de las Naciones Unidas para el Derecho Mercantil Internacional, o UNCITRAL por sus siglas en inglés.

15 Ley Modelo de la CNUDMI sobre Arbitraje Comercial Internacional 1985 con las enmiendas aprobadas en 2006, Comisión de las Naciones Unidas para el Derecho Mercantil Internacional, Naciones Unidas, 2088, p.9.

16 Artículo 1432.- El tribunal arbitral estará facultado para decidir sobre su propia competencia, incluso sobre las excepciones relativas a la existencia o validez del acuerdo de arbitraje. A ese efecto, la cláusula compromisoria que forme parte de un contrato se considerará como un acuerdo independiente de las demás estipulaciones del contrato. La decisión de un tribunal arbitral declarando nulo un contrato, no entrañará por ese solo hecho la nulidad de la cláusula compromisoria. (Énfasis añadido) 
Este principio tiene su asiento en el hecho de que entre acuerdo arbitral y el contrato que lo contiene no existe propiamente un nexo de accesoriedad o dependencia, sino que se trata de dos relaciones jurídicas distintas y autónomas. ${ }^{17}$

Francisco González de Cossío ${ }^{18}$ advierte sobre esta dualidad de relaciones y precisa que el destino del acuerdo arbitral se encuentra disociado del contrato principal:

El análisis de validez del acuerdo arbitral es jurídicamente distinto del análisis de validez de la relación que lo contiene. Ello significa, en el argot del derecho de las obligaciones, que cuando las partes celebran un contrato con un acuerdo arbitral, jurídicamente entablan no una sino dos relaciones jurídicas. Y cada una se cocina aparte.

En la práctica del arbitraje comercial, doméstico e internacional, encontramos una franca inclinación por la separabilidad del acuerdo arbitral. Los principales reglamentos de arbitraje, institucionales e internacionales, incluyen en su contenido la referencia expresa a este principio.

Así, por ejemplo, el artículo 21.2 del Reglamento de Arbitraje de la CNUDMI establece en lo conducente: "Una cláusula compromisoria que forme parte de un contrato y que disponga la celebración del arbitraje con arreglo al presente Reglamento se considerará como un acuerdo independiente de las demás estipulaciones del contrato". ${ }^{19}$

Por su parte, el Reglamento de Arbitraje de la Cámara de Comercio Internacional (ICC por sus siglas en inglés) señala en su artículo 6.9:

Salvo estipulación en contrario y siempre y cuando haya admitido la validez del acuerdo de arbitraje, el tribunal arbitral no perderá su competencia por causa de pretendida nulidad o inexistencia del contrato. El tribunal arbitral conservará su competencia, aun en caso de inexistencia o nulidad del contrato, para determinar los respectivos derechos de las partes y decidir sobre sus pretensiones y alegaciones. ${ }^{20}$

El artículo 11 de las Reglas de Arbitraje del Centro de Arbitraje de México (CAM), bajo el título "Autonomía del acuerdo de arbitraje", dispone al efecto:

La posible nulidad o inexistencia del contrato o convenio no implica la incompetencia del Tribunal Arbitral si éste admite la validez del acuerdo de arbitraje. El Tribunal Arbitral continúa siendo competente, incluso en caso de inexistencia o de nulidad del contrato, para determinar los derechos respectivos de las partes y pronunciarse sobre sus Demandas y conclusiones. ${ }^{21}$

17 Cfr. PEREZNIETO, Leonel y GRAHAM, James A., Tratado de Arbitraje Comercial Internacional Mexicano, Colección Mediación - Arbitraje, México, Limusa, 2009, pp. 129 y 130.

18

19 Reglamento de Arbitraje de la Comisión de las Naciones Unidas para el Derecho Mercantil Internacional, https://www.uncitral.org/pdf/spanish/texts/arbitration/arb-rules/arb-rules-s.pdf.

20 Reglamento de Arbitraje de la Cámara de Comercio Internacional, vigente a partir del $1^{\circ}$ de marzo de 2017 , https://cdn.iccwbo.org/content/uploads/sites/3/2017/03/ICC-2017-Arbitration-and-2014-Mediation-Rulesspanish-version.pdf.

21 Reglas de Arbitraje del Centro de Arbitraje de México, https://camex.com.mx/wp/wp-content/uploads/2017/11/ reglas-de-arbitraje-del-cam-adoptadas-por-arias-mexico.pdf. 
Es de concluirse - por ende- que son efectos básicos del principio de separabilidad: a) que el acuerdo arbitral no necesariamente sigue la suerte del contrato en que se contiene; b) que el acuerdo arbitral puede estar sujeto a un régimen legal distinto al del contrato que lo incluye; y c) que el tribunal arbitral puede resolver sobre su propia competencia. ${ }^{22}$ Cabe añadir como consecuencia lógica derivada de las consideraciones que hemos venido haciendo, que para darse el supuesto de que el acuerdo arbitral se viese afectado de inexistencia o nulidad, las causas de tales ineficacias tendrían que incidir de manera directa sobre los elementos de existencia o requisitos de validez del propio acuerdo arbitral, independientemente de las que pudieran referirse al contrato que generó la relación jurídica subyacente respecto de la cual se pactó la sujeción al arbitraje en caso de controversia.

\section{IMPACTO DE LA NOVACIÓN SOBRE EL ACUERDO ARBITRAL Y EFECTOS POSTERIORES}

Con base en lo expuesto hasta ahora, reiteramos evidentemente la conclusión en el sentido de que la novación de una relación jurídica no tiene el efecto de extinguir por sí sola el acuerdo arbitral establecido por las partes con miras a resolver las controversias que en su caso derivasen de dicha relación, debido a la separabilidad o autonomía del convenio arbitral. También ha quedado claro que, si la intención expresa de las partes al llevar a cabo la novación es suprimir la cláusula arbitral, por supuesto ésta no subsistirá, de manera que para que la obligación naciente cuente con una cláusula de sujeción al arbitraje debe pactarse nuevamente al efecto; de lo contrario, las controversias que deriven de la nueva obligación se habrán de resolver por vía judicial.

Ahora bien, reconociendo la subsistencia del acuerdo arbitral después de la extinción por novación de la relación jurídica a la cual estaba dirigido, una cuestión que debe dilucidarse de entrada es si ese pacto arbitral que sobrevive pasa a la nueva obligación, vinculando a las partes al arbitraje tal como en la anterior. Por la afirmativa se pronuncian algunas voces, como la de Jesús Córdoba Schaefer: ${ }^{23}$

En efecto, al tratarse de dos contratos distintos, al novar una obligación, la cláusula arbitral perdura o sobrevive y se impregna en la nueva obligación; mientras que las partes también pueden optar por la novación del acuerdo arbitral, siendo entonces importante esa intención de animus novandi, también de la novación del acuerdo arbitral, cambiándola por otra forma de solución de controversias, como es el caso de optar por la jurisdicción ordinaria [...].

[...] nuestra conclusión principal sobre este punto es que en los casos de cesión, novación y subrogación o cualquier otro contrato que implique la transmisión de derechos y obligaciones a otra parte, se debe presumir que el convenio arbitral se transfiere con ella, salvo que las partes acuerden expresamente lo contrario. (Énfasis añadido)

22 GONZÁLEZ DE COSSÍO, Francisco, p. 283.

23 CÓRDOVA, Jesús, "La vinculación del convenio arbitral en los contratos de cesión o de la mal llamada transmisión de la cláusula arbitral”, Informe práctico de arbitraje, Actualidad Jurídica, Perú, núm. 240, noviembre 2013, pp. 84-91. 
En México no se han dado pronunciamientos judiciales que aborden particularmente este problema. Sin embargo, en las decisiones de nuestros Tribunales Federales se cuenta con una tesis aislada que, en una interpretación a contrario sensu, podría dar lugar a pensar en la transferencia del acuerdo arbitral de la obligación original a la nueva, en caso de novación:

Arbitraje mercantil. criterios para determinar la ineficacia del acuerdo de. Un acuerdo de arbitraje es ineficaz cuando hay algún motivo por el cual no puede producir efectos, por lo que son causas de ineficacia del acuerdo arbitral aquellas que impiden que se produzcan sus efectos, positivos o negativos, ya sea porque las partes no están facultadas y obligadas a someterse al arbitraje, o debido a que es imposible plantear la diferencia ante un tribunal estatal. Así, no podrán generarse los efectos del arbitraje si existe una renuncia de ambas partes al mismo, dado que esa voluntad es prioritaria en la conformación del acuerdo y debe atenderse a ella, como se tiene que respetar en el caso opuesto, esto es, cuando se pacte el convenio arbitral, en atención a que la voluntad de las partes es la base toral de las convenciones mercantiles. Desde luego, esa renuncia deberá constar de manera expresa e indubitable, porque de esa misma forma tiene que obrar el acuerdo arbitral en aras de la certeza y de la constatación del efectivo consentimiento en comprometer, y la exigencia que para ese acuerdo se impone debe también, por identidad de razón, regir en cuanto a la dimisión al compromiso. Tampoco podrán surtirse los efectos del arbitraje si hay una novación de la cláusula arbitral, pues en tal caso se sustituirá el compromiso de someterse al arbitraje por el pacto de sujetarse a la jurisdicción estatal, es decir, una obligación primigenia por una posterior, acorde a la naturaleza de esa figura que se regula en el artículo 2213 del Código Civil Federal. De la misma forma, si el plazo en que debía acudirse al arbitraje, en caso de existir pacto sobre esa vigencia temporal o aplicarse el previsto legalmente de manera genérica, ha fenecido, porque en tal caso opera la prescripción en su vertiente negativa, liberadora de obligaciones, conforme a los artículos 1135 y 1158 del Código Civil Federal, en relación con los artículos 1038 y 1047 del Código de Comercio. Similar imposibilidad de producción de efectos del pacto arbitral se dará si un tribunal estatal resolvió la controversia sin oposición de las partes, o cuando la sentencia judicial ha causado ejecutoria, dada la firmeza que ello produce y el respeto que debe darse a la cosa juzgada, lo cual impedirá a las partes someter al arbitraje una cuestión ya fallada por un órgano del Estado, quien tampoco podrá hacer la remisión correspondiente. La muerte o incapacidad de los árbitros, en caso de que hayan sido designados nominalmente en el convenio arbitral y no se haya previsto en este último la posibilidad de sustituirlos, también provoca que no pueda producir efectos dicho pacto, dado que no habrá tribunal arbitral que conozca del asunto y al cual deba remitir la autoridad judicial. Los anteriores supuestos relacionados con la falta de capacidad para que el acuerdo de arbitraje surta sus efectos, esto es, con su ineficacia, son enunciativos y no limitativos, ciertamente, pero revelan que el juzgador que se pronuncia sobre esa cuestión debe constreñirse a verificar si existe un motivo que impida que los referidos efectos se produzcan. ${ }^{24}$ (Énfasis añadido)

24 Semanario Judicial de la Federación y su Gaceta, Novena Época, t. XXII, diciembre de 2005, tesis I.3o.C.521 C, p. 2623. 
En efecto, al establecer la tesis de referencia que los efectos del arbitraje tampoco podrán surtir si hay novación de la cláusula arbitral, sustituyéndose en este caso el compromiso de someterse al arbitraje por el de sujetarse a la jurisdicción estatal, podría interpretarse a contrario sensu que, si no hay novación de la cláusula arbitral, entonces los efectos del arbitraje sí podrán darse en relación con la nueva obligación, sin sustituirse el acuerdo arbitral por el de sometimiento a la jurisdicción estatal.

En nuestra opinión, la consideración sobre la supuesta transferencia del acuerdo arbitral de la obligación antigua a la nueva en caso de novación resulta por demás incorrecta. Basta con poner atención al concepto que de acuerdo de arbitraje se establece de forma generalizada en la legislación arbitral a todo nivel. Por ejemplo, la Ley Modelo de la CNUDMI sobre Arbitraje Comercial Internacional lo define en los términos siguientes:

ArTículo 7. Definición del acuerdo de arbitraje

El "acuerdo de arbitraje" es un acuerdo por el que las partes deciden someter a arbitraje todas las controversias o ciertas controversias que hayan surgido o puedan surgir entre ellas respecto de una determinada relación jurídica, contractual o no. (Énfasis añadido)

Siguiendo esa misma línea, nuestro código de comercio precisa en la fracción primera del artículo 1416:

ARTículo 1416.- Para los efectos del presente título se entenderá por:

I.- Acuerdo de arbitraje, el acuerdo por el que las partes deciden someter a arbitraje todas o ciertas controversias que hayan surgido o puedan surgir entre ellas respecto de una determinada relación jurídica, contractual o no contractual. El acuerdo de arbitraje podrá adoptar la forma de una cláusula compromisoria incluida en un contrato o la forma de un acuerdo independiente. (Énfasis añadido)

En España, la vigente Ley de Arbitraje ${ }^{25}$ señala:

ARTículo 9. Forma y contenido del convenio arbitral.

1. El convenio arbitral, que podrá adoptar la forma de cláusula incorporada a un contrato o de acuerdo independiente, deberá expresar la voluntad de las partes de someter a arbitraje todas o algunas de las controversias que hayan surgido o puedan surgir respecto de una determinada relación jurídica, contractual o no contractual. (Énfasis añadido)

Se destaca en todos estos preceptos - y es común denominador prácticamente en todas las legislaciones arbitrales del mundo- que el acuerdo de voluntades de las partes para someter a arbitraje las posibles diferencias que surjan entre ellas, está referido de manera específica a una determinada relación jurídica, la que evidentemente no puede ser otra más que aquélla para la que se produjo de inicio el convenio arbitral.

25 Ley 60/2003, de 23 de diciembre, de Arbitraje y de regulación del arbitraje institucional en la Administración General del Estado, y su reforma por la Ley 11/2011, de 20 de mayo. 
Los comentaristas del Instituto Mexicano de Arbitraje ${ }^{26}$ se pronuncian al respecto bajo la misma directriz, cuando al realizar la interpretación del artículo 1416 del código de comercio en torno al concepto de acuerdo de arbitraje, confirman que se trata de un acuerdo mediante el cual las partes deciden someterse al arbitraje a fin de resolver controversias que deriven de una determinada relación jurídica.

En otras palabras, el arbitraje comercial no puede plantearse respecto de controversias en abstracto ni sobre disputas que deriven de relaciones que no sean de naturaleza jurídica - por ejemplo, de tipo familiar o moral-, sino que en todo caso requiere haber una relación jurídica subyacente y es respecto de ésta que las partes pueden convenir en dirimir por la vía del arbitraje las diferencias que se susciten, siempre que estén dentro del ámbito de aplicación del Título Cuarto, desde luego. ${ }^{27}$ (Énfasis añadido)

La referencia a una relación jurídica determinada -y no a otra - también se puntualiza en el texto de las cláusulas modelo de sujeción al arbitraje que proponen las más prestigiadas instituciones administradoras a nivel nacional e internacional. Por ejemplo, la cláusula modelo sugerida por el Centro de Arbitraje de México (CAM) establece: "Todas las desavenencias que deriven de este contrato serán resueltas definitivamente de acuerdo con las Reglas de Arbitraje del Centro de Arbitraje de México (CAM), por uno o más árbitros nombrados conforme a dichas Reglas". (Énfasis añadido)

Por su parte, la cláusula modelo de la Cámara Nacional de Comercio de la Ciudad de México (CANACO) señala: "Todo litigio, controversia o reclamación resultante de este contrato o relativo a este contrato, su incumplimiento, resolución o nulidad, se resolverá mediante arbitraje de conformidad con el Reglamento de Arbitraje de la Cámara Nacional de Comercio de la Ciudad de México". (Énfasis añadido)

La Comisión de las Naciones Unidas para el Derecho Mercantil Internacional (CNUDMI o UNCITRAL por sus siglas en inglés), plantea la siguiente cláusula modelo de arbitraje: "Todo litigio, controversia o reclamación resultante de este contrato o relativo a este contrato, su incumplimiento, resolución o nulidad, se resolverá mediante arbitraje de conformidad con el Reglamento de Arbitraje de la CNUDMI". (Énfasis añadido)

En todas estas cláusulas modelo se aprecia claramente que el acuerdo de voluntades de las partes para someterse al arbitraje se dirige en forma específica y exclusiva a las controversias que deriven de la relación jurídica contractual en que se concreta la cláusula, sin que pueda entenderse que el mismo acuerdo aplica también con relación a las diferencias que resulten de alguna otra relación jurídica, aun cuando ésta vincule a las mismas partes, y mucho menos si se trata de una obligación sustancialmente diferente, como es la que nace como consecuencia de la novación.

26 El Instituto Mexicano de Arbitraje es una asociación civil cuya finalidad es el fomento y desarrollo del arbitraje, principalmente el comercial, nacional e internacional, que agrupa a los más destacados especialistas en la materia.

Instituto Mexicano de Arbitraje, Legislación mexicana de arbitraje comentada, México, Porrúa, 2015, p. 19. 
A todo esto, no podemos perder de vista que el acuerdo arbitral es un contrato y como tal está sujeto a las reglas previstas al efecto por la legislación civil. En tal virtud, le resulta aplicable lo dispuesto por el artículo 1796 de los códigos civiles tanto Federal y para el Distrito Federal, en cuanto a que desde que se perfeccionan los contratos, "obligan a los contratantes no solo al cumplimiento de lo expresamente pactado, sino también a las consecuencias que, según su naturaleza son conforme a la buena fe, al uso o a la ley".

Entonces, es indiscutible que, en razón del contenido de la cláusula arbitral, las partes quedan obligadas a lo expresamente pactado en ella, es decir, al sometimiento al arbitraje por las posibles controversias que llegasen a surgir de la relación jurídica que la contiene y no de otra totalmente distinta, como lo es la nueva obligación - sustancialmente diferente - que se crea en la novación a la par de la extinción de la obligación anterior.

Es claro que los términos de la cláusula arbitral dejan cabal y expresa evidencia de la intención de las partes respecto de cuál es la relación jurídica específica sobre la que recae su obligación de sujeción al arbitraje en caso de controversia, sin que pueda suponerse en forma alguna que su acuerdo de voluntades se extiende a otra u otras obligaciones, salvo que se hubiera convenido expresamente en ese sentido. Atendemos por supuesto a lo dispuesto por los artículos 1851 y 1852 de los citados códigos civiles, cuyo texto en ambos ordenamientos es como sigue:

ArTículo 1851.- Si los términos de un contrato son claros y no dejan duda sobre la intención de los contratantes, se estará al sentido literal de sus cláusulas.

Si las palabras parecieren contrarias a la intención evidente de los contratantes, prevalecerá ésta sobre aquéllas.

ArTículo 1852.- Cualquiera que sea la generalidad de los términos de un contrato, no deberán entenderse comprendidos en él cosas distintas y casos diferentes de aquéllos sobre los que los interesados se propusieron contratar.

Por consiguiente, debemos entender que aun cuando la novación no provoca la extinción del acuerdo arbitral, sino que lo deja "vivo" por efecto del principio de separabilidad, no puede ser que dicho acuerdo subsistente sirva ahora en sus términos para obligar a las partes a acudir al arbitraje en caso de desavenencias derivadas de una relación jurídica distinta, para la cual no fue convenida la cláusula arbitral en cuestión.

Esto es así porque, en la novación, el expreso propósito de quienes la llevan a cabo es suprimir absolutamente la obligación que originalmente los vincula, con todo cuanto de hecho y por derecho le corresponde, y sustituirla por otra totalmente diferente - animus novandi- Si la voluntad de las partes no se manifiesta con este objetivo de manera expresa, no habrá novación. ${ }^{28}$

Además, se ha hecho notar previamente que el acuerdo arbitral no tiene carácter accesorio respecto de la relación jurídica obligacional que lo contiene.

28 Este mismo criterio ha sido sostenido por la Suprema Corte de Justicia de la Nación en tesis aislada bajo el rubro: Novación no existe si no hay vinculación jurídica entre los contratos celebrados. Semanario Judicial de la Federación, Séptima Época, Tercera Sala, Volumen 145-150, Cuarta Parte, p. 387. 
Por esta razón, no le atañe la disposición del artículo 2220 de nuestros precitados códigos civiles, la que en ambos ordenamientos hace referencia al hecho de que la novación extingue la obligación principal y las obligaciones accesorias, con la posibilidad de que el acreedor, por una reserva expresa, impida la extinción de las obligaciones accesorias, que entonces pasarían a la nueva. Resultaría francamente impensable e improcedente que por una reserva expresa "del acreedor" - lo que evidentemente supone una decisión unilateral-, el acuerdo arbitral previsto para la obligación primitiva pudiera "pasar" a la nueva.

Ahora bien, si de conformidad con lo expuesto entendemos: a) que la novación produce el efecto de extinguir por completo la obligación primigenia pero no el acuerdo arbitral previsto para ella, dado el principio de autonomía o separabilidad que lo rige; b) que el acuerdo arbitral que sobrevive a la extinción por novación de la obligación original que lo contempla no trasciende a la nueva; c) que si la intención de las partes en la novación es la de que la nueva relación jurídica prevenga su obligación de someterse al arbitraje en caso de posibles controversias derivadas de ella, tendrían que convenir nuevamente en ese sentido; entonces, ¿cuál es la razón jurídica de la subsistencia del acuerdo arbitral — con "vida propia"-, después de la extinción por novación de la obligación a la que estaba vinculado?

Para responder a este planteamiento debemos poner sobre la mesa algunas consideraciones de importancia. Primeramente, para entrar al análisis del impacto de la novación sobre el acuerdo arbitral, es necesario corroborar si al realizarse fueron cumplidos todos los requisitos que exige la ley para la eficacia de esta particular forma de extinción de las obligaciones, adicionalmente a los que son comunes a todos los contratos, conforme a las previsiones de nuestros multicitados códigos civiles. ${ }^{29}$

En efecto, para que la novación surta plenamente sus efectos deben cubrirse a cabalidad tanto los elementos de existencia como los requisitos de validez que le corresponden en función de su naturaleza contractual, en términos de los artículos 1794 y 1795 de los códigos civiles tanto Federal como para el Distrito Federal, ${ }^{30}$ en correlación con las disposiciones que en dichos ordenamientos se establecen de manera específica en materia de nulidad de la novación:

ARTículo 2218. La novación es nula si lo fuere también la obligación primitiva, salvo que la causa de nulidad solamente pueda ser invocada por el deudor, o que la ratificación convalide los actos nulos en su origen.

ARTículo 2219. Si la novación fuere nula, subsistirá la antigua obligación.

29 El artículo 2214 establece en ambos ordenamientos: "La novación es un contrato, y como tal, está sujeta a las disposiciones respectivas, salvo las modificaciones siguientes".

30 Artículo 1794. Para la existencia del contrato se requiere:

I. Consentimiento;

II. Objeto que pueda ser materia del contrato.

Artículo 1795. El contrato puede ser invalidado:

I. Por incapacidad legal de las partes o de una de ellas;

II. Por vicios del consentimiento;

III. Por su objeto, o su motivo o fin sea ilícito;

IV. Porque el consentimiento no se haya manifestado en la forma que la ley establece. 
Bajo esta premisa, y en aras de alcanzar una respuesta a la interrogante planteada sobre la razón y utilidad de la subsistencia quia posterum del acuerdo arbitral tras la novación de la obligación que lo contiene, tenemos que reconocer que en la hipótesis de que la novación haya tenido lugar en observancia completa de los requisitos legales que le aplican, es decir, si la novación se llevó a cabo en forma jurídicamente correcta, la conclusión evidente es que se producirá la extinción de la relación jurídica que contiene el acuerdo arbitral y consecuentemente este último, que sobrevive, se habrá quedado sin materia y sin posibilidad de ejecución.

En estas condiciones, pareciera que no existe razón que justifique la permanencia del convenio original de arbitraje con posterioridad al momento en que se verifica el acto jurídico novatorio. Sin embargo, esto no es así, por lo menos no del todo.

La pregunta obligada es: ¿para qué sirve entonces que el acuerdo arbitral subsista y permanezca vigente después de la novación?

No olvidemos que la novación es una figura contractual que puede verse afectada de inexistencia o de nulidad por no reunir los correspondientes elementos de existencia o los requisitos necesarios para su validez y que, además, la ley indica que la novación será nula si lo fuere igualmente la obligación primitiva. En todos estos supuestos subsistirá la antigua obligación.

Bajo esta perspectiva, la respuesta viable a mi parecer es en el sentido de que el pacto arbitral que subsiste con posterioridad a la novación tendrá eficacia precisamente en la hipótesis de que se planteen controversias sobre la existencia o validez del propio acto jurídico de la novación. En estos casos, el acuerdo de arbitraje que sobrevive a la extinción de la primera obligación tiene el alcance de vincular tales controversias a efecto de que sea el tribunal arbitral quien las resuelva. Lógicamente, la decisión del tribunal arbitral habrá de consistir, sin otra opción, en la declaración relativa a la improcedencia de la novación por razón de su inexistencia o nulidad, o bien, en la confirmación de su validez y eficacia con todas sus repercusiones.

En el primer supuesto, si la novación es declarada nula o inexistente por el tribunal arbitral, evidentemente no puede surtir efectos y, a la luz de la previsión del artículo 2219 de nuestros códigos civiles, subsistirá la antigua obligación. Claro es que, si esto ocurre, el acuerdo arbitral continuará en vigor en los términos y condiciones originalmente convenidos.

En el segundo supuesto, si el tribunal arbitral se pronuncia a favor de la plena eficacia de la novación, quedará confirmada la extinción de la relación jurídica específica respecto de la cual pactaron las partes el sometimiento al arbitraje en caso de surgir diferencias derivadas de la misma y, en consecuencia, el acuerdo arbitral de referencia se habrá quedado sin materia a partir de entonces y sin posibilidad futura de ejecución, no obstante su consabida permanencia "con vida propia" después de operar la novación, gracias a la fuerza que le imprime el principio de autonomía o separabilidad. 
Más allá, no quedan a la vista otros alcances o aplicaciones de este acuerdo arbitral "supérstite", que permanece a futuro - quía posterum - tras la extinción de la obligación a la que estuvo ligado.

\section{CONCLUSIONES}

En virtud del principio de autonomía o separabilidad del acuerdo arbitral, éste y la obligación que lo contiene constituyen dos relaciones jurídicas claramente diferentes e independientes, de manera tal que las vicisitudes que pueden afectar a una de ellas no van a afectar a la otra. Como consecuencia, la novación que extinga la relación jurídica específica respecto de la cual convinieron las partes la sujeción al arbitraje en caso de controversias derivadas de ella, no tiene el efecto de extinguir por sí sola este acuerdo arbitral, sino que sobrevive a la novación.

Evidentemente, por elemental aplicación del principio de la autonomía de la voluntad, si la intención de las partes en la novación es que la nueva obligación siga contemplando la obligación de acudir al arbitraje en caso de desavenencias que surjan de ella, por supuesto pueden pactarlo así, pero no se tratará de una "reserva" del acuerdo arbitral original como sucede con las obligaciones accesorias, sino de un nuevo convenio de arbitraje celebrado entre dichas partes, en relación directa y exclusiva con esa nueva obligación.

Aunque el acuerdo de arbitraje no se extingue por la novación y subsiste en sus términos con posterioridad, no se transmite a la nueva obligación. En todo caso, las partes tendrían que llevar a cabo un nuevo acuerdo de voluntades para incluir una cláusula arbitral que aplique de manera específica para la obligación naciente.

El acuerdo arbitral que sobrevive a la extinción de la obligación primitiva a causa de la novación, tendrá eficacia solo en el supuesto de que se susciten controversias sobre la existencia o validez del propio acto jurídico de la novación, quedando su resolución a cargo del tribunal arbitral.

En caso de que la resolución del tribunal arbitral declare nula o inexistente la novación, subsistirá la antigua obligación y naturalmente el pacto de arbitraje respectivo seguirá teniendo aplicación respecto de las posibles controversias que deriven de dicha relación jurídica, que fue precisamente el objeto para el que se estableció desde su origen por las partes. Si, por el contrario, la decisión del tribunal arbitral sostiene la validez y efectividad de la novación, el resultado será que el acuerdo arbitral queda sin objeto y sin posibilidad de ejecución posterior, toda vez que dejó de existir la relación jurídica para la cual fue convenido de manera específica y exclusiva.

\section{BIBLIOGRAFÍA}

BORJA SORIANO, Manuel, Teoría General de las Obligaciones, 21a. ed., México, S.A., 2009.

GONZÁLEZ DE COSSÍO, Francisco, Arbitraje, 4a. ed., México, Porrúa, S.A., 2014. 
INSTITUTO MEXICANO DE ARBITRAJE, Legislación mexicana de arbitraje comentada, México, 2015.

PEREZNIETO, Leonel y GRAHAM, James A., Tratado de Arbitraje Comercial Internacional Mexicano, Colección Mediación - Arbitraje, México, Editorial Limusa, 2009.

PLANIOL, Marcel y RIPERT, Georges, Tratado elemental de derecho civil, t. IV: Las obligaciones, 2a. ed., trad. de Jorge M. Cajica Jr., México, Cárdenas Editor y Distribuidor, 1991.

REDFERN, Alan y HUNTER, Martin et al., Teoría y práctica del arbitraje comercial internacional, 4a. ed. en español revisada y adaptada por Noiana Marigo y Felipe Ossa, Editorial Aranzadi, Navarra, 2007.

RICO ÁLVAREZ, Fausto, et al., Tratado teórico-práctico de derecho de obligaciones, 1a. ed., México, Editorial Porrúa, S.A., 2013.

SANCHO REBULLIDA, Francisco de A., La novación de las obligaciones, Barcelona, Ediciones Nauta, S.A., 1964.

Hemerografía

CÓRDOVA SCHAEFER, Jesús, "La vinculación del convenio arbitral en los contratos de cesión o de la mal llamada transmisión de la cláusula arbitral", Informe práctico de arbitraje, Actualidad Jurídica, Perú, núm. 240, noviembre 2013.

FOLLONIER-AYALA, Alejandro, "Evolución latinoamericana de los principios de separabilidad y kompetenz-kompetenz", Revista Latinoamericana de Derecho Comercial Internacional, Vol.2, Núm. 2, Año 2014.

Otras fuentes

FLORES RUEDA, Cecilia (edit.), Diccionario Enciclopédico de Arbitraje Comercial, México, Themis, S.A. de C. V., 2011. 